OPEN ACCESS

Edited by:

Vasileios-Arsenios Lioutas, Beth Israel Deaconess Medical Center and Harvard Medical School,

United States

Reviewed by:

Deren Wang,

West China Hospital of Sichuan

University, China

Archana Hinduja,

The Ohio State University,

United States

${ }^{*}$ Correspondence:

Xingquan Zhao

zxq@vip.163.com

Yongjun Wang

yongjunwang@ncrcnd.org.cn

Specialty section:

This article was submitted to

Stroke

a section of the journal

Frontiers in Neurology

Received: 02 December 2020 Accepted: 08 February 2021

Published: 08 March 2021

Citation:

Gao B, Gu H, Yu W, Liu S, Zhou Q, Kang $K$, Zhang J, Li Z, Zhao $X$ and Wang Y (2021) Admission Dehydration Is Associated With Significantly Lower In-Hospital Mortality After Intracerebral

Hemorrhage.

Front. Neurol. 12:637001.

doi: 10.3389/fneur.2021.637001

\section{Admission Dehydration Is Associated With Significantly Lower In-Hospital Mortality After Intracerebral Hemorrhage}

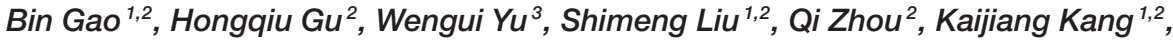 \\ Jia Zhang ${ }^{1,2}$, Zixiao $\mathrm{Li}^{1,2}$, Xingquan Zhao ${ }^{1,2,4 *}$ and Yongjun Wang ${ }^{1,2 *}$ \\ ${ }^{1}$ Department of Neurology, Beijing Tiantan Hospital, Capital Medical University, Beijing, China, ${ }^{2}$ China National Clinical \\ Research Center for Neurological Diseases, Beijing, China, ${ }^{3}$ Department of Neurology, University of California, Irvine, Irvine, \\ CA, United States, ${ }^{4}$ Research Unit of Artificial Intelligence in Cerebrovascular Disease, Chinese Academy of Medical \\ Sciences, Beijing, China
}

Background and Purpose: Our aim was to investigate the frequency of dehydration at admission and associations with in-hospital mortality in patients with intracerebral hemorrhage $(\mathrm{ICH})$.

Methods: Data of consecutive patients with ICH between August 2015 and July 2019 from the China Stroke Center Alliance (CSCA) registry were analyzed. The patients were stratified based on the blood urea nitrogen (BUN) to creatinine (CR) ratio (BUN/CR) on admission into dehydrated (BUN/CR $\geq 15$ ) or non-dehydrated (BUN/CR $<15$ ) groups. Data were analyzed with multivariate logistic regression models to investigate admission dehydration status and the risks of death at hospital.

Results: A total number of 84,043 patients with $\mathrm{ICH}$ were included in the study. The median age of patients on admission was 63.0 years, and $37.5 \%$ of them were women. Based on the baseline BUN/CR, 59,153 (70.4\%) patients were classified into dehydration group. Patients with admission dehydration (BUN/CR $\geq 15$ ) had $13 \%$ lower risks of in-hospital mortality than those without dehydration (BUN/CR $<15$, adjusted $\mathrm{OR}=0.87$, $95 \% \mathrm{Cl}$ 0.78-0.96). In patients aged $<65$ years, admission dehydration was associated with $19 \%$ lower risks of in-hospital mortality (adjusted OR $=0.81,95 \% \mathrm{Cl} 0.70-0.94$. adjusted $p=0.0049$ ) than non-dehydrated patients.

Conclusion: Admission dehydration is associated with significantly lower in-hospital mortality after $\mathrm{ICH}$, in particular, in patients $<65$ years old.

Keywords: intracranial hemorrhage, dehydration, mortality, blood urea nitrogen, creatinine

\section{INTRODUCTION}

Stroke was the second leading cause of deaths and disability globally in 2017, and acute intracerebral hemorrhage (ICH) accounted for $26 \%$ of all strokes (1). Dehydration is common and associated with poor outcomes in ischemic stroke (2-4). Correlation between admission dehydration and mortality of ICH during hospitalization remains unclear. The ratio of blood urea nitrogen/creatinine (BUN/CR) $\geq 15$ was considered as ideal biomarker of dehydration, 
especially in patients with normal kidney function (3-5). We aimed to investigate the relationship between admission dehydration and in-hospital mortality in a large $\mathrm{ICH}$ cohort from a multicenter prospective registry.

\section{METHODS}

\section{Data Availability}

Data are available to researchers on request for the purpose of reproducing the results or replicating the procedure by directly contacting the corresponding authors.

\section{China Stroke Center Alliance Registry}

This study was approved by the Human Studies Institutional Review Board of Beijing Tiantan hospital. The data of patients were prospectively collected and retrospectively analyzed from the China Stroke Center Alliance (CSCA) registry. The CSCA is a national, multicenter, hospital-based, voluntary, multifaceted intervention and continuous quality improvement (QI) initiative. This multifaceted intervention includes stroke center development, written care protocols, workshops, and a monitoring and feedback system of evidence-based performance measures. The data coordinating center of the CSCA resides at the China National Clinical Research Center for Neurological Diseases and Beijing Tiantan Hospital. The CSCA registry enrolled 1,006,798 patients diagnosed as acute ischemic stroke (AIS), transient ischemic attack (TIA), ICH, or subarachnoid hemorrhage from August 1, 2015, to July 31, 2019. Patients > 18 years of age were enrolled within 7 days of symptom onset. The CSCA registry collects data through an internet-based tool (Medicine Innovation Research Center, Beijing, China). Only in-hospital data were recorded, as follow-up data were not available. All participating hospitals in the CSCA were approved to collect data without requiring individual patient informed consent under the common rule or a waiver of authorization and exemption from their institutional review board (6). The study was performed according to the principles included in the Declaration of Helsinki.

\section{Patient Recruitment and Data Collection}

Between August 2015 and July 2019, 85,705 patients with acute ICH were enrolled in the CSCA registry, and 1,662 of them were excluded for the study due to missing BUN or CR data. Therefore, 84,043 patients diagnosed with ICH were included for our study (Figure 1). ICH was diagnosed according to the World Health Organization criteria combined with imaging data by doctors in local hospital (7).

The patients were divided into dehydrated and nondehydrated groups according to the ratio of BUN (mg/dL)/CR (mg/dl). BUN/CR $\geq 15$ was defined as the dehydrated group, and BUN/CR $<15$ was defined as the non-dehydrated group according to previous reports $(3-5,8)$.

Abbreviations: ICH, intracerebral hemorrhage; BUN, blood urea nitrogen; CR, creatinine; BUN/CR, the ratio of blood urea nitrogen to creatinine; CSCA, China Stroke Center Alliance; eGFR, estimated glomerular filtration rate; OR, odds ratios; $\mathrm{CI}$, confidence interval; IQR, interquartile range.
Demographic data, stroke risk factors, and medical history, including age, sex, previous history of intracranial hemorrhage, hypertension, liver insufficiency or kidney insufficiency, current smoking and drinking, the use of antiplatelet, anticoagulation, antihypertensive, or diabetic medication, were abstracted from the registry. Laboratory test results, including fasting blood glucose, homocysteine, and admission BUN and CR levels were also extracted (Table 1).

All laboratory data were the initial test results at admission. Estimated glomerular filtration rate (eGFR) were calculated by a modified four-variable Chronic Kidney Disease Epidemiology Collaboration (CKD-EPI) formula with an adjusted coefficient of 1.1 for the Chinese population to estimate eGFR (9): $\mathrm{eGFR}_{\mathrm{CKD}-\mathrm{EPI}}=141 \times \min (\mathrm{CR} / \kappa, 1)^{\alpha} \times \max (\mathrm{CR} / \kappa, 1)^{-1.209} \times$ $0.993^{\text {Age }} \times 1.018$ (if female) $\times 1.1$, where CR was creatinine, $\kappa$ was 0.7 for females and 0.9 for males, $\alpha$ was -0.329 for females and -0.411 for males, min was the minimum of $\mathrm{CR} / \kappa$ or 1 , and max indicated the maximum of $\mathrm{CR} / \kappa$ or 1 . In-hospital mortality was collected as primary outcome, which was defined as all-cause death during hospitalization. In the CSCA registry, all variables and data were locally collected or adjudicated by doctors at each site.

\section{Statistical Analysis}

Categorical variables were reported as absolute numbers with percentages, and continuous variables were reported as median along with interquartile range (IQR). We analyzed the differences in baseline characteristics between the two groups. An absolute standardized difference (ASD) of $>10 \%$ indicates significant differences in the variable between two groups (10). We used ASD $>10 \%$ in univariate analysis to select out covariables that need to be adjusted for in the multivariable regression model. Covariates associated with outcomes reported in the medical literature, even if $\mathrm{ASD}<10 \%$, were also included in the multivariable regression model. For dichotomous outcomes, we used hierarchical binary logistic regression to determine adjusted odds ratios (aORs) and 95\% confidence intervals (CIs) after median imputation of missing data (11). Missing data were minimal ( $\geq 98 \%$ complete) with the exceptions of fast blood glucose (missing in $1.2 \%$ ) and homocysteine (15\%). We performed group analysis for the association of BUN/CR with in-hospital mortality according to age ( $<65$ or $\geq 65$ years), sex, medical histories, smoking status, drinking, and renal function based on eGFR $(\leq 60$ or $>60 \mathrm{~mL} / \mathrm{min} / 1.73 \mathrm{~m}^{2}$ ). All tests were two-sided, and $p$-value $<0.05$ was considered statistically significant. Interaction terms were retained only when the interaction $p$-value was $<0.05$. All statistical analyses were performed using SAS Version 9.4 software (SAS Institute, Cary, NC, USA).

\section{RESULTS}

In this large cohort study, 84,043 patients met the inclusion criteria. The median age of the patients was 63.0 years (53.072.0), and $37.5 \%$ of the patients were women. Among these patients, $59,153(70.4 \%)$ were classified into the dehydration group (BUN/CR $\geq 15)$ and 24,890 (29.6\%) into the nondehydrated group $(\mathrm{BUN} / \mathrm{CR}<15)$ (Figure 1). Table 1 shows 


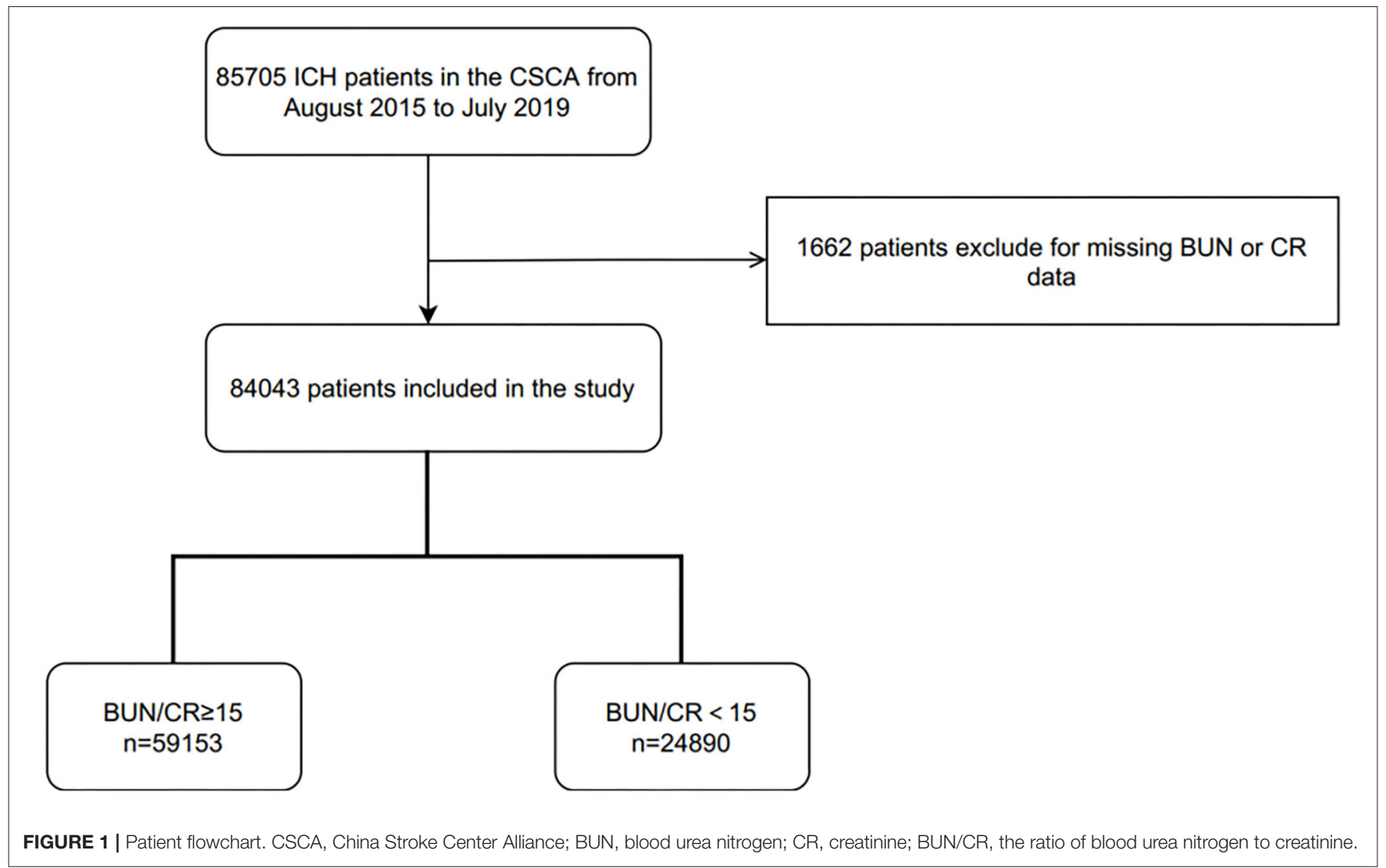

clinical profiles of the two groups according to hydration status at admission. Patients with dehydration at admission were older (median age, 64.0 [IQR, 54.0-73.0] vs. 61.0 [IQR, 51.0-70.0]). They were also more likely to have a history of smoking, alcohol consumption, or liver/renal insufficiency and higher homocysteine level.

The in-hospital mortality of the entire study cohort was $2.3 \%$ $(1,915 / 84,043)$. It was significantly lower in the dehydration group than in the non-dehydration group $(2.2 \%$ vs. $2.5 \%$, unadjusted OR 0.86, 95\%CI 0.78-0.95, $p=0.0029$ ) (Table 2). Admission dehydration was associated with $13 \%$ lower inhospital mortality after adjusting for confounders (adjusted OR $=0.87,95 \%$ CI $0.78-0.96, p=0.0050)$.

There was an interaction between age and BUN/CR ratio on the in-hospital mortality ( $p=0.0211$ ) (Table 2 ). In subgroup analysis, the dehydration group was associated with significantly lower in-hospital mortality than the non-dehydration group only in patients $<65$ years old ( 1.61 vs. $2.2 \%, p<0.0001$ ). There was $19 \%$ lower risk of in-hospital mortality in the dehydration group (adjusted OR $=0.81,95 \% \mathrm{CI} 0.70-0.94, p=0.0049$ ). Of note, there was no difference in in-hospital mortality between the two groups in patients aged 65 or older $(2.79$ vs. $2.98 \%, p<0.3094)$.

Further analyses of the interaction effects of sex, hypertension, diabetes, current smoking, drinking, and renal function on the association between dehydration and in-hospital mortality of patients with ICH showed that none of those interaction factors had a significant effect on the association (all of them $p>0.05$ ), although the OR values for some subgroups were significant (Table 2).

\section{DISCUSSION}

Our study provided evidence that admission dehydration was associated with $13 \%$ lower risk of in-hospital mortality in ICH patients (adjusted OR $=0.87,95 \%$ CI 0.78-0.96, $p=0.0050$ ). Most importantly, subgroup analysis showed that admission dehydration was associated with $19 \%$ lower risk of all-cause death in hospital in patients $<65$ years old (adjusted OR $=0.81,95 \% \mathrm{CI}$ $0.70-0.94, p=0.0049$ ).

Although dehydration is a risk factor of early neurological deterioration (END) after AIS (12-14), the effect of dehydration on outcome after ICH remains unclear.

To the best of our knowledge, only one previous study focused on the relationship between admission dehydration based on the ratio of BUN/CR $\geq 15$ and the prognosis of hemorrhagic stroke, and there was no difference on discharge outcomes including modified Rankin scale (mRS) and Barthel index (BI) between dehydrated $(B U N / C R \geq 15)$ and non-dehydrated $(B U N / C R<$ 15) groups (3).

Different from AIS, ICH may cause immediate elevation of intracranial pressure, mass effect, and impending herniation at initial presentation. Admission dehydration might be associated with lower mass effect and herniation following ICH than the non-dehydrated cohort. We analyzed data from a large 
TABLE 1 | Baseline characteristics of stroke patients according to dehydration status based on the ratio of BUN/CR.

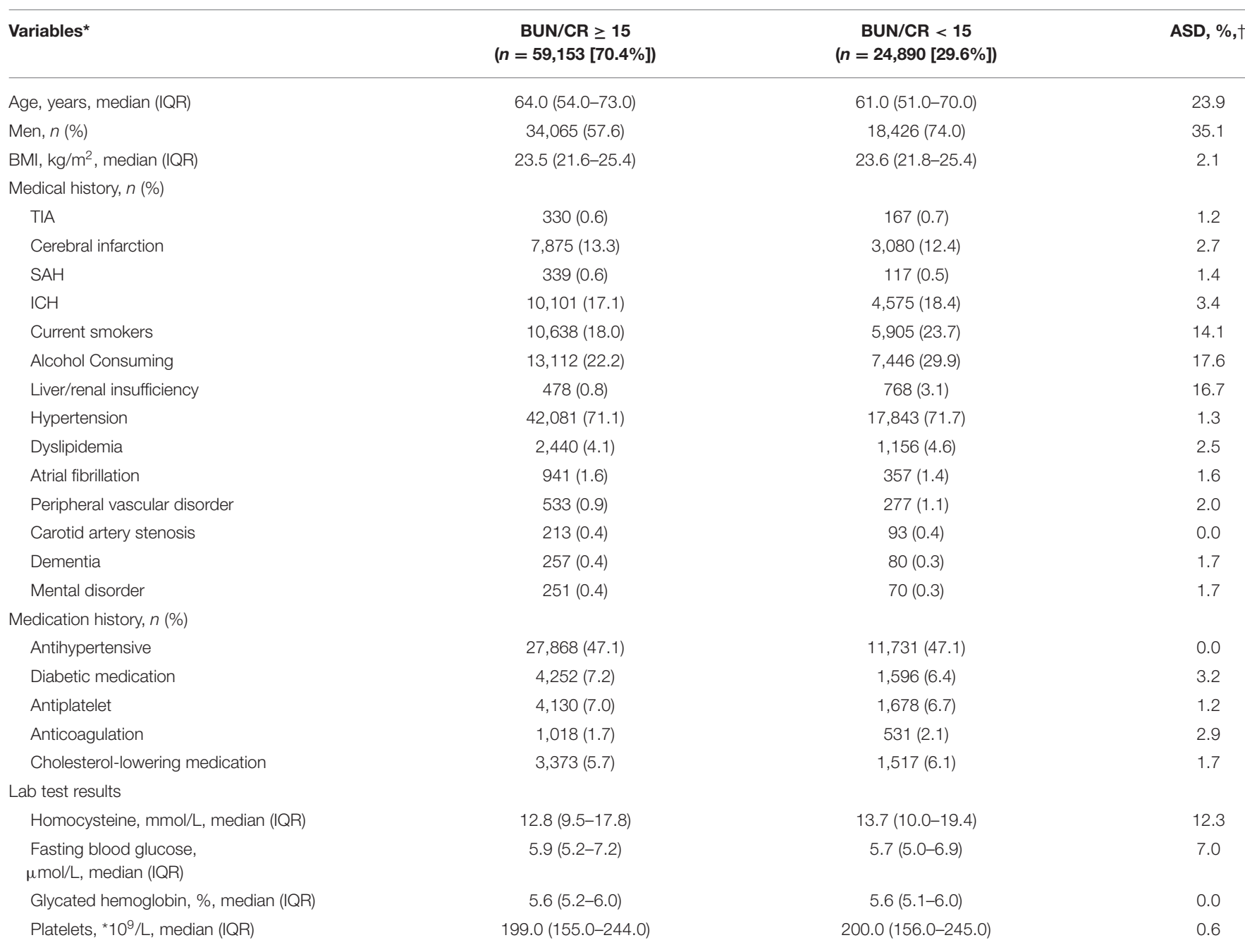

ICH, intracranial hemorrhage; IQR, interquartile range; BMI, body mass index; TIA, transient ischemic attacks; SAH, subarachnoid hemorrhage.

"Continuous variables were presented as median (interquartile range), and category variables were presented as counts (percentages).

${ }^{\dagger}$ An absolute standardized difference (ASD) of >10\% indicates significant differences in the variable between two groups.

multicenter prospective registry to investigate admission dehydration and in-hospital mortality after ICH. We found that admission dehydration was associated with significantly lower in-hospital mortality, in particular, in patients $<65$ years old. The mechanisms of the effect are unclear. There are a few possibilities: (1) dehydration is known to increase blood viscosity and to decrease blood pressure and cerebral perfusion $(4,15)$, leading to reduced hematoma growth and good in-hospital outcome $(16,17)$. (2) Dehydration-related hypovolemia and hypernatremia may increase intravascular osmolality and reduce perihematomal edema and intracranial pressure (18-22).

This large cohort study has provided sufficient statistical power to ensure the robustness of the findings. However, our study has a few limitations. First, BUN/CR ratio is not a reliable biomarker of dehydration, in particular, in patients with congestive heart failure, gastrointestinal bleeding, or urinary tract obstruction. We were unable to exclude patients with these confounding conditions. Second, imaging data were unavailable, so it was uncertain whether the effect of BUN/CR on mortality is related to the size or location of the hematoma. Third, ICH severity on admission was not collected in our study. Last, the management of dehydration after admission was unknown. The relative benefit of admission dehydration vs. persistent dehydration remains unclear.

\section{CONCLUSIONS}

This multicenter, large-scale prospective cohort study demonstrates the predictive value of initial hydration status on in-hospital mortality after ICH. An additional study combined with more biomarkers of dehydration, imaging data, 
TABLE 2 | Associations between dehydration status and in-hospital mortality and subgroup analysis.

\begin{tabular}{|c|c|c|c|c|c|c|c|c|c|}
\hline \multirow[t]{2}{*}{ Group } & \multirow{2}{*}{$\begin{array}{l}\text { No. of } \\
\text { patients }\end{array}$} & \multicolumn{2}{|c|}{ No. of death/total patients (\%) } & \multicolumn{3}{|c|}{ Unadjusted } & \multicolumn{3}{|c|}{ Adjusted ** } \\
\hline & & $\begin{array}{c}\text { BUN/CR }<15^{*} \\
n=24,890\end{array}$ & $\begin{array}{c}\text { BUN/CR } \geq 15 n \\
=59,153\end{array}$ & OR $(95 \% \mathrm{Cl})$ & $p$-value & Interaction $p$ & OR $(95 \% \mathrm{Cl})$ & $p$-value & Interaction $p$ \\
\hline Overall & 84,043 & $\begin{array}{c}626 / 24,890 \\
(2.5)\end{array}$ & $\begin{array}{c}1,289 / 59,153 \\
(2.2)\end{array}$ & $\begin{array}{c}0.86 \\
(0.78-0.95)\end{array}$ & $0.0029, \dagger$ & / & $\begin{array}{c}0.87 \\
(0.78-0.96)\end{array}$ & $0.0050, \dagger$ & / \\
\hline \multicolumn{10}{|l|}{ Age } \\
\hline$\geq 65$ years & 38,630 & $\begin{array}{c}296 / 9,922 \\
(2.98)\end{array}$ & $\begin{array}{c}800 / 28,708 \\
(2.7)\end{array}$ & $0.930 .81-1.07)$ & 0.3094 & 0.011 & $\begin{array}{c}0.97 \\
(0.84-1.12)\end{array}$ & 0.6758 & 0.0211 \\
\hline$<65$ years & 45,413 & $\begin{array}{c}330 / 14,968 \\
(2.20)\end{array}$ & $\begin{array}{c}489 / 30,445 \\
(1.61)\end{array}$ & $\begin{array}{c}0.72 \\
(0.63-0.83)\end{array}$ & $<0.0001, \dagger$ & & $\begin{array}{c}0.81 \\
(0.7-0.94)\end{array}$ & $0.0049, \dagger$ & \\
\hline \multicolumn{10}{|l|}{ Sex } \\
\hline Male & 52,491 & $\begin{array}{c}467 / 18,426 \\
(2.53)\end{array}$ & $\begin{array}{c}777 / 34,065 \\
(2.28)\end{array}$ & $\begin{array}{c}0.90 \\
(0.80-1.01)\end{array}$ & 0.0685 & 0.448 & $\begin{array}{c}0.89 \\
(0.79-1.00)\end{array}$ & $0.0467, \dagger$ & 0.8855 \\
\hline Female & 31,552 & $\begin{array}{c}159 / 6,464 \\
(2.46)\end{array}$ & $\begin{array}{c}512 / 25,088 \\
(2.04)\end{array}$ & $\begin{array}{c}0.83 \\
(0.69-0.99)\end{array}$ & $0.0376, \dagger$ & & $\begin{array}{c}0.83 \\
(0.69-1.01)\end{array}$ & 0.0580 & \\
\hline \multicolumn{10}{|c|}{ Hypertension } \\
\hline Yes & 59,924 & $\begin{array}{c}454 / 17,843 \\
(2.54)\end{array}$ & $\begin{array}{c}911 / 42,081 \\
(2.16)\end{array}$ & $\begin{array}{c}0.85 \\
(0.76-0.95)\end{array}$ & $0.0044, \dagger$ & 0.55 & $\begin{array}{c}0.85 \\
(0.76-0.96)\end{array}$ & $0.009, \dagger$ & 0.4475 \\
\hline No & 24,119 & $\begin{array}{c}172 / 7,047 \\
(2.44)\end{array}$ & $\begin{array}{c}378 / 17,072 \\
(2.21)\end{array}$ & $\begin{array}{c}0.91 \\
(0.75-1.09)\end{array}$ & 0.2838 & & $\begin{array}{c}0.89 \\
(0.73-1.07)\end{array}$ & 0.2175 & \\
\hline \multicolumn{10}{|l|}{ Diabetic } \\
\hline Yes & 8,005 & $\begin{array}{c}100 / 2,205 \\
(4.54)\end{array}$ & $\begin{array}{c}203 / 5,800 \\
(3.50)\end{array}$ & $\begin{array}{c}0.76 \\
(0.60-0.97)\end{array}$ & $0.0305, \dagger$ & 0.312 & $\begin{array}{c}0.74 \\
(0.57-0.95)\end{array}$ & $0.0202, \dagger$ & 0.4352 \\
\hline No & 76,038 & $\begin{array}{c}526 / 22,685 \\
(2.32)\end{array}$ & $\begin{array}{c}1,086 / 53,353 \\
(2.04)\end{array}$ & $\begin{array}{c}0.88 \\
(0.79-0.97)\end{array}$ & $0.0132, \dagger$ & & $\begin{array}{c}0.90 \\
(0.81-1.01)\end{array}$ & 0.0618 & \\
\hline \multicolumn{10}{|c|}{ Current smoker } \\
\hline Yes & 16,543 & $\begin{array}{c}125 / 5,905 \\
(2.12)\end{array}$ & $\begin{array}{c}211 / 10,638 \\
(1.98)\end{array}$ & $\begin{array}{c}0.94 \\
(0.75-1.17)\end{array}$ & 0.5601 & 0.385 & $\begin{array}{c}0.91 \\
(0.73-1.15)\end{array}$ & 0.4318 & 0.9158 \\
\hline No & 67,500 & $\begin{array}{c}501 / 18,985 \\
(2.64)\end{array}$ & $\begin{array}{c}1,078 / 48,515 \\
(2.22)\end{array}$ & $\begin{array}{c}0.84 \\
(0.75-0.93)\end{array}$ & $0.0139, \dagger$ & & $\begin{array}{c}0.86 \\
(0.77-0.96)\end{array}$ & $0.0077, \dagger$ & \\
\hline \multicolumn{10}{|c|}{ Alcohol consumption } \\
\hline Yes & 20,558 & $\begin{array}{c}197 / 7,446 \\
(2.65)\end{array}$ & $\begin{array}{c}310 / 13,112 \\
(2.36)\end{array}$ & $\begin{array}{c}0.89 \\
(0.74-1.07)\end{array}$ & 0.2113 & 0.759 & $\begin{array}{c}0.90 \\
(0.75-1.08)\end{array}$ & 0.2559 & 0.974 \\
\hline No & 63,485 & $\begin{array}{c}429 / 17,444 \\
(2.46)\end{array}$ & $\begin{array}{c}979 / 46,041 \\
(2.13)\end{array}$ & $\begin{array}{c}0.86 \\
(0.77-0.97)\end{array}$ & $0.0111, \dagger$ & & $\begin{array}{c}0.86 \\
(0.76-0.97)\end{array}$ & $0.0136, \dagger$ & \\
\hline \multicolumn{10}{|c|}{ Chronic renal dysfunction, $\ddagger$} \\
\hline Yes & 8,792 & $\begin{array}{c}355 / 6,001 \\
(5.92)\end{array}$ & $\begin{array}{c}171 / 279 \\
(6.13)\end{array}$ & $\begin{array}{c}1.04 \\
(0.86-1.25)\end{array}$ & 0.6959 & 0.013 & $\begin{array}{c}0.99 \\
(0.81-1.21)\end{array}$ & 0.9373 & 0.067 \\
\hline No & 75,251 & $\begin{array}{c}271 / 18,889 \\
(1.43)\end{array}$ & $\begin{array}{c}1,118 / 56,362 \\
(1.98)\end{array}$ & $\begin{array}{c}1.39 \\
(1.22-1.59)\end{array}$ & $<0.0001, \dagger$ & & $\begin{array}{c}1.22 \\
(1.06-1.40)\end{array}$ & $0.0049, \dagger$ & \\
\hline
\end{tabular}

$O R$, odds ratio; $B U N / C R$, the ratio of blood urea nitrogen to creatinine.

${ }^{*}$ As reference group.

${ }^{*}$ Adjusted for age, male, current smokers, alcohol consuming, liver/renal insufficiency, medical history of intracranial hemorrhage (ICH), hypertension, antihypertensive, diabetic medication, antiplatelet, anticoagulation, homocysteine, and fasting blood glucose.

tp-value $<0.05$.

$\ddagger$ Chronic renal dysfunction defined by estimated glomerular filtration rate (eGFR) $\leq 60 \mathrm{~mL} / \mathrm{min} / 1.73 \mathrm{~m}^{2}$. 
and long-term outcomes is warranted to investigate the effect of admission dehydration on survival after $\mathrm{ICH}$, in particular, in young patient population.

\section{DATA AVAILABILITY STATEMENT}

The raw data supporting the conclusions of this article will be made available by the authors, without undue reservation.

\section{ETHICS STATEMENT}

The studies involving human participants were reviewed and approved by Human Studies Institutional Review Board of Beijing Tiantan hospital. The ethics committee waived the requirement of written informed consent for participation.

\section{AUTHOR CONTRIBUTIONS}

BG: designed the study and drafted the manuscript. HG, KK, JZ, QZ, and SL: major role in data acquisition and revised the manuscript for intellectual content. ZL and WY revised the

\section{REFERENCES}

1. Krishnamurthi RV, Ikeda T, Feigin VL. Global, regional and countryspecific burden of ischaemic stroke, intracerebral haemorrhage and subarachnoid haemorrhage: a systematic analysis of the global burden of disease study 2017. Neuroepidemiology. (2020) 54:171-9. doi: 10.1159/0005 06396

2. Rowat A, Graham C, Dennis M. Dehydration in hospital-admitted stroke patients: Detection, frequency, and association. Stroke. (2012) 43:8579. doi: 10.1161/STROKEAHA.111.640821

3. Liu CH, Lin SC, Lin JR, Yang JT, Chang YJ, Chang CH, et al. Dehydration is an independent predictor of discharge outcome and admission cost in acute ischaemic stroke. Eur J Neurol. (2014) 21:1184-91. doi: 10.1111/ene. 12452

4. Schrock JW, Glasenapp M, Drogell K. Elevated blood urea nitrogen/creatinine ratio is associated with poor outcome in patients with ischemic stroke. Clin Neurol Neurosurg. (2012) 114:881-4. doi: 10.1016/j.clineuro.2012. 01.031

5. Shi Z, Zheng WC, Yang H, Fu XL, Cheng WY, Yuan WJ. Contribution of dehydration to end in acute ischemic stroke not mediated via coagulation activation. Brain Behav. (2019) 9:e01301. doi: 10.1002/ brb3.1301

6. Wang Y, Li Z, Wang Y, Zhao X, Liu L, Yang X, et al. Chinese stroke center alliance: a national effort to improve healthcare quality for acute stroke and transient ischaemic attack: Rationale, design and preliminary findings. Stroke Vasc Neurol. (2018) 3:256-62. doi: 10.1136/svn-2018000154

7. Stroke-1989. Recommendations on stroke prevention, diagnosis, and therapy. Report of the who task force on stroke and other cerebrovascular disorders. Stroke. (1989) 20:1407-31. doi: 10.1161/01.STR.20. 10.1407

8. Bahouth MN, Gottesman RF, Szanton SL. Primary 'dehydration' and acute stroke: a systematic research review. J Neurol. (2018) 265:216781. doi: 10.1007/s00415-018-8799-6

9. Teo BW, Xu H, Wang D, Li J, Sinha AK, Shuter B, et al. Gfr estimating equations in a multiethnic asian population. Am J Kidney Dis. (2011) 58:56-63. doi: 10.1053/j.ajkd.2011.0 2.393 manuscript for intellectual content. YW and XZ: designed and conceptualized the study, analyzed the data, and drafted and revised the manuscript. All authors contributed to the article and approved the submitted version.

\section{FUNDING}

Funding was provided by CAMS Innovation Fund for Medical Sciences (2019-I2M-5-029), Beijing Municipal Committee of Science and Technology (Z201100005620010), and Beijing Natural Science Foundation (Z200016). This study was supported by the Research Unit of Artificial Intelligence in Cerebrovascular Disease, Chinese Academy of Medical Sciences, Beijing, China.

\section{ACKNOWLEDGMENTS}

We thank the staff and participants of the CSCA registry for their contribution.
10. Austin PC. Balance diagnostics for comparing the distribution of baseline covariates between treatment groups in propensity-score matched samples. Stat Med. (2009) 28:3083-107. doi: 10.1002/sim.3697

11. van der Heijden GJ, Donders AR, Stijnen T, Moons KG. Imputation of missing values is superior to complete case analysis and the missingindicator method in multivariable diagnostic research: a clinical example. J Clin Epidemiol. (2006) 59:1102-9. doi: 10.1016/j.jclinepi.2006. 01.015

12. Bhatia K, Mohanty S, Tripathi BK, Gupta B, Mittal MK. Predictors of early neurological deterioration in patients with acute ischaemic stroke with special reference to blood urea nitrogen (bun)/creatinine ratio \& urine specific gravity. Indian J Med Res. (2015) 141:299-307. doi: 10.4103/0971-5916. 156564

13. Bahouth MN, Gaddis A, Hillis AE, Gottesman RF. Pilot study of volume contracted state and hospital outcome after stroke. Neurol Clin Pract. (2018) 8:21-6. doi: 10.1212/CPJ.0000000000 000419

14. Lin LC, Fann WC, Chou MH, Chen HW, Su YC, Chen JC. Urine specific gravity as a predictor of early neurological deterioration in acute ischemic stroke. Med Hypotheses. (2011) 77:11-4. doi: 10.1016/j.mehy.2011.03.012

15. Frey MA, Lathers C, Davis J, Fortney S, Charles JB. Cardiovascular responses to standing: Effect of hydration. J Clin Pharmacol. (1994) 34:38793. doi: 10.1002/j.1552-4604.1994.tb04978.x

16. Li Q, Warren AD, Qureshi AI, Morotti A, Falcone GJ, Sheth KN, et al. Ultra-early blood pressure reduction attenuates hematoma growth and improves outcome in intracerebral hemorrhage. Ann Neurol. (2020) 88:38895. doi: 10.1002/ana.25793

17. Toyoda K, Koga M, Yamamoto H, Foster L, Palesch YY, Wang Y, et al. Clinical outcomes depending on acute blood pressure after cerebral hemorrhage. Ann Neurol. (2019) 85:105-13. doi: 10.1002/ana.25379

18. Diringer MN, Scalfani MT, Zazulia AR, Videen TO, Dhar R. Cerebral hemodynamic and metabolic effects of equi-osmolar doses mannitol and $23.4 \%$ saline in patients with edema following large ischemic stroke. Neurocrit Care. (2011) 14:11-7. doi: 10.1007/s12028-010-9465-8

19. Koenig MA, Bryan M, Lewin JL III, Mirski MA, Geocadin RG, Stevens RD. Reversal of transtentorial herniation with hypertonic saline. Neurology. (2008) 70:1023-9. doi: 10.1212/01.wnl.0000304042.055 57.60 
20. Qureshi AI, Wilson DA, Traystman RJ. Treatment of elevated intracranial pressure in experimental intracerebral hemorrhage: comparison between mannitol and hypertonic saline. Neurosurgery. (1999) 44:1055-63. doi: 10.1097/00006123-199905000-00064

21. Qureshi AI, Wilson DA, Traystman RJ. Treatment of transtentorial herniation unresponsive to hyperventilation using hypertonic saline in dogs: effect on cerebral blood flow and metabolism. J Neurosurg Anesthesiol. (2002) 14:2230. doi: 10.1097/00008506-200201000-00005

22. Cook AM, Morgan Jones G, Hawryluk GWJ, Mailloux P, McLaughlin D, Papangelou A, et al. Guidelines for the acute treatment of cerebral edema in neurocritical care patients. Neurocrit Care. (2020) 32:64766. doi: 10.1007/s12028-020-00959-7
Conflict of Interest: The authors declare that the research was conducted in the absence of any commercial or financial relationships that could be construed as a potential conflict of interest.

Copyright (C) 2021 Gao, Gu, Yu, Liu, Zhou, Kang, Zhang, Li, Zhao and Wang. This is an open-access article distributed under the terms of the Creative Commons Attribution License (CC BY). The use, distribution or reproduction in other forums is permitted, provided the original author(s) and the copyright owner(s) are credited and that the original publication in this journal is cited, in accordance with accepted academic practice. No use, distribution or reproduction is permitted which does not comply with these terms. 